\title{
Bioma Amazônia: atos e fatos
}

\section{JACQUES MARCOVITCH ${ }^{I}$ e VANESSA PINSKY II}

\section{Introdução}

$\mathrm{E}$ NTRE 2019 e 2020 o desmatamento na Amazônia e as queimadas elevaram-se a níveis exponenciais, prejudicando seriamente a imagem do Brasil no exterior. Chefes de Estado e destacados membros da comunidade científica, lideranças empresariais e dirigentes de organizações da sociedade civil manifestaram sua extrema preocupação com o aumento alarmante das taxas de desmatamento no grande bioma. Fundos de investimentos e coalizões empresariais criticaram veementemente a conduta institucional que facilitou os perigosos eventos. A Noruega e a Alemanha, principais doadores ao Fundo Amazônia, registraram sua insatisfação com a política ambiental do governo federal. Em síntese, ampliou-se cada vez mais, no exterior e na cena interna, um clamor tão aceso quanto as labaredas que ameaçam a maior biodiversidade vegetal do mundo.

Este artigo expõe a questão em todas as suas variáveis e apresenta uma agenda propositiva para reverter o presente quadro, que põe em risco a mais relevante experiência de REDD+ na atual conjuntura. Se o Estado brasileiro quer efetivamente recuperar o Fundo Amazônia, quais as medidas que precisa tomar? No texto que segue, a partir de antecedentes esta questão é respondida.

A despeito dos erros de governos passados em outras áreas, o Brasil provou sua capacidade de reduzir drasticamente a taxa de desmatamento na Amazônia, desde 2004, por meio de um conjunto de políticas públicas transversais. De acordo com o Projeto de Monitoramento do Desmatamento da Amazônia (Prodes), coordenado pelo Instituto Nacional de Pesquisas Espaciais (Inpe), a taxa de desmatamento na Amazônia Legal brasileira diminuiu $72 \%$ no período 2004-2018 (Inpe, 2018). Essa redução está relacionada ao estabelecimento de áreas protegidas, sistemas de monitoramento eficazes, ações de comando e controle, moratórias da soja e da carne, queda nos preços das commodities, e mecanismos de restrição de crédito para proprietários de terras que desmatam ilegalmente (Aguiar et al., 2020; Moutinho et al., 2016).

Destaca-se também o Plano de Ação para Prevenção e Controle do Desmatamento na Amazônia Legal (PPCDAm), criado em 2004, principal instrumento da política pública ambiental brasileira, que tem como objetivos reduzir o desmatamento e criar as condições para se estabelecer um modelo de desenvolvimento sustentável na Amazônia Legal. Até 2018, o PPCDAm integrava as políticas públicas de combate ao desmatamento dos estados, sendo que sua execução contava com ações de mais de uma dezena de ministérios, articuladas 
em torno de quatro eixos temáticos: 1) ordenamento fundiário e territorial; 2) monitoramento e controle ambiental; 3 ) fomento às atividades produtivas sustentáveis, e 4) instrumentos econômicos e normativos (MMA, 2020).

Tais acertos, porém, não prosperaram no atual governo. A taxa de desmatamento aumentou 34\% durante o período 2018-2019 (Inpe, 2020), sugerindo que as políticas públicas em curso têm sido insuficientes para manter o declínio da curva e enfrentar os vetores do desmatamento na Amazônia devido às atuais circunstâncias do país. É nesse contexto do aumento crescente do desmatamento, potencializado pelo sistemático desmonte das políticas ambientais no Brasil, e por uma retórica do governo federal de desinformação e de incompatibilidade do desenvolvimento econômico da região amazônica com a preservação ambiental, que se insere o presente estudo.

Muitos argumentam que o aumento da escalada da destruição da floresta amazônica está diretamente relacionado com a percepção de impunidade por grileiros de terras e extrativistas ilegais envolvidos em atividades como mineração e madeira, resultado dos discursos e atos do bolsonarismo, os ataques aos dados do Inpe, a fragilização do Ibama e dos instrumentos de monitoramento das florestas.

O Fundo Amazônia é fundamental para o financiamento de projetos experimentais e inovadores, que apresentem potencial de escala para mitigar as emissões, promovendo o desenvolvimento da região Amazônica. Recebe doações voluntárias de recursos não reembolsáveis para ações de prevenção, monitoramento e combate ao desmatamento, na conservação e no uso sustentável da Amazônia Legal (Decreto n.6.527/2008). Além disso, até 20\% dos recursos do fundo podem ser destinados ao desenvolvimento de sistemas de monitoramento e controle do desmate no restante do Brasil e em outros países com florestas tropicais (BNDES, 2019).

O mecanismo de captação de recursos do Fundo Amazônia é baseado nos resultados obtidos na redução das emissões oriundas do desmatamento na Amazônia brasileira. Com isso, o Fundo captou cerca de R \$ 3,4 bilhões em doações, sendo $93,8 \%$ do governo da Noruega, $5,7 \%$ do governo da Alemanha, e 0,5\% da Petrobras. Até final de 2019, o Fundo apresentava uma carteira de 103 projetos apoiados, dos quais 27 estão concluídos. Os recursos financeiros alocados aos projetos apoiados somam cerca de R \$ 1,86 bilhão. Desse valor, 63\% já foram desembolsados. Com relação à natureza das instituições apoiadas, $61 \%$ representam o setor público, $38 \%$ o terceiro setor e apenas $1 \%$ de origem internacional (BNDES, 2019). São dados que contrariam a retórica do Ministério do Meio Ambiente sobre a inconsistência dos projetos apoiados e são encontrados em documentos de uma instituição oficial, o BNDES.

O Fundo Amazônia está paralisado desde meados de 2019, devido a mudanças de prioridades e na sua estrutura de governança impostas unilateralmente pelo governo federal, o que levou a desentendimentos entre o governo Bolsona- 
ro e doadores internacionais. As análises e aprovações de novos projetos foram suspensas, resultando no congelamento de recursos já ingressados no Fundo Amazônia na ordem de R \$ 1,54 bilhão. A captação de doações ao Fundo Amazônia também foi suspensa com a publicação do Decreto n.10.144/2019, revogando o artigo $2^{\circ}$ do Decreto n.6.527 /2008, que autorizava "o BNDES a proceder captações de doações e emitir diploma reconhecendo a contribuição dos doadores ao Fundo Amazônia" (BNDES, 2019, p.11). Um novo ciclo de atuação do Fundo Amazônia deve ser estabelecido, mas as negociações ainda não haviam sido encerradas entre o Brasil e doadores internacionais até a conclusão destas análises.

O objetivo principal deste artigo é discutir uma agenda propositiva para a retomada do Fundo Amazônia. Para isso, equívocos da gestão pública em nível federal são analisados à luz dos compromissos assumidos pelo Brasil em acordos internacionais de cooperação.

Organiza-se em cinco seções. Na primeira é discutido o contexto da criação do Fundo Amazônia em 2008 até a sua suspensão em 2019. Na segunda seção avaliamos os principais fatos e atos do atual governo que têm contribuído para o desmonte da política ambiental no país. Na terceira seção é discutida a recente inserção da pauta ambiental na agenda econômica, em consequência da pressão de fundos de investimentos internacionais e ameaças de boicotes a produtos brasileiros, bem como a resposta de seus fabricantes. Na quarta seção, propomos uma agenda para a retomada do Fundo Amazônia.

\section{O maior e mais importante experimento de REDD+ no mundo}

A ideia que norteou a criação do Fundo Amazônia veio de pesquisadores e do governo brasileiro, em 2007, durante a $13^{a}$ Conferência das Partes da UNFCCC (COP-13). Foi autorizada pelo BNDES em 2008, a partir de um acordo de cooperação internacional entre os governos do Brasil e da Noruega, que se comprometeu a doar até USD 1 bilhão, mediante a apresentação de resultados em mitigação (Decreto n.6.527/2008). Esse foi o primeiro mecanismo de financiamento do clima internacional baseado na lógica de pagamentos por resultados. Passou a receber doações voluntárias para investimentos não reembolsáveis em ações de prevenção, monitoramento e combate ao desmatamento, e promoção da conservação e do uso sustentável da Amazônia Legal. Os projetos apoiados devem ter alinhamento com o PPCDAm, a Estratégia Nacional de REDD+ (ENREDD+), planos estaduais de prevenção e combate ao desmatamento, diretrizes e critérios estabelecidos pelo Comitê Orientador do Fundo Amazônia (Cofa), e Políticas Operacionais do BNDES (BNDES, 2019).

O mecanismo de captação do Fundo Amazônia baseia-se em resultados alcançados pelo Brasil na redução de emissões de carbono oriundas do desmatamento e degradação florestal (REDD+ na sigla em inglês). REDD+ significa "reduzir emissões de gases de efeito estufa oriundas do desmatamento e da degradação florestal, conservação de estoques de carbono florestal, manejo sus- 
tentável de florestas e aumento de estoques de carbono florestal" (UNFCCC, 2014 , p.6). Como se vê, trata-se de um instrumento engenhoso de financiamento, que leva países desenvolvidos a destinar compensação financeira aos países em desenvolvimento, e com grandes blocos florestais, que implementarem políticas públicas e iniciativas com foco em mitigação em mudanças climáticas. O REDD+ foi chancelado oficialmente pela UNFCCC em 2013, como mecanismo de financiamento do clima baseado em resultados e ratificado no Acordo de Varsóvia, além de constar no Acordo de Paris de 2015. Nesses protocolos, os países desenvolvidos se comprometem a financiar ações de mitigação das emissões de GEE nos países em desenvolvimento.

O caráter inovador da iniciativa gerou excelentes resultados no Brasil com a redução drástica do desmatamento na Amazônia. Entre 2004 e 2018, convém reiterar, a taxa do desmatamento na Amazônia Legal foi reduzida em 72\% (Inpe, 2018), considerado o mais elevado índice de redução em todo o mundo nas emissões resultantes de desmatamento florestal. Outros fatores contribuíram para a captação de recursos de REDD+, como a capacidade institucional do Brasil em governança (Wolosin et al., 2016), gestão e transparência do BNDES, monitoramento por satélite da taxa de desmatamento pelo Inpe, e efetividade das ações de comando e controle por meio de políticas ambientais desde 2004, especificamente o PPCDAm (Marcovitch; Pinsky, 2014; Pinsky et al., 2019).

Alguns resultados das ações apoiadas pelo Fundo Amazônia incluem: 1 milhão de imóveis rurais inscritos no Cadastro Ambiental Rural (CAR); 1.236 missões de fiscalização ambiental efetuadas; 338 instituições apoiadas diretamente e por meio de parceiros; 193 mil pessoas beneficiadas com atividades produtivas sustentáveis; 190 unidades de conservação apoiadas; 65\% da área das terras indígenas da Amazônia apoiadas, e 594 publicações científicas ou informativas produzidas (BNDES, 2019).

O BNDES, gestor do Fundo, é responsável por contratar e monitorar os projetos apoiados, além de divulgar as atividades e os resultados. Até o 2018, as principais instâncias de governança de REDD+ no Brasil eram baseadas na Comissão Nacional de REDD+ (CONAREDD+), responsável pela coordenação e implementação da estratégia nacional, o Comitê Gestor do Fundo Amazônia (Cofa) e o Comitê Técnico do Fundo Amazônia (CTFA). O Cofa, formado por representantes do governo federal, dos governos estaduais e da sociedade civil, determinava as diretrizes e acompanhava os resultados do Fundo. Já o CTFA, formado por especialistas independentes, atestava as reduções de emissões de gases de efeito estufa oriundas do desmatamento. Esses três arranjos institucionais, baseados em uma abordagem de governança participativa acordadas com doadores internacionais, eram fundamentais para dar transparência à iniciativa.

Em maio de 2019, o ministro Ricardo Salles anunciou em coletiva de imprensa, na sede do Ibama, em São Paulo, que o Ministério do Meio Ambiente (MMA) tinha analisado projetos de organizações da sociedade civil, apoiados 
pelo Fundo Amazônia, e encontrara diversos contratos com algum grau de inconsistência. No entanto, não citou quais eram os contratos, nem evidências dos problemas encontrados. A Controladoria Geral da União (CGU) não participou de nenhuma auditoria envolvendo as contas do Fundo Amazônia, e o Tribunal de Contas da União (TCU), responsável pela auditoria do Fundo Amazônia, aprovou em 2018 as últimas prestações de contas.

O Cofa e o CTFA foram extintos em 28 de junho de 2020 com a promulgação do Decreto n.9.759/2019, que estabeleceu regras para colegiados da administração pública federal. A decisão unilateral do governo brasileiro de desestruturar a governança do Fundo Amazônia não foi aceita pelos países doadores. Negociações foram iniciadas entre os países, mas até a conclusão deste estudo não houve avanços para um entendimento comum sobre nova governança que satisfizesse as partes. As análises e aprovações de novos projetos foram suspensas em 2019, sendo mantido apenas o fluxo de desembolsos dos projetos já aprovados. Além disso, o governo federal revogou, em 28 de novembro de 2019, a autorização do BNDES para captar recursos e emitir diplomas aos países doadores do Fundo Amazônia (Decreto n.10.144/2019).

A suspensão de novas doações da Noruega e da Alemanha ao Fundo Amazônia deu-se a partir de agosto de 2019, justificada pelo aumento da taxa de desmatamento na Amazônia e pelas negociações travadas por exigências do ministro Salles. Os principais pontos de conflito com os doadores internacionais foram: 1) a ausência de uma base legal e técnica para continuar financiando o Fundo com o desmonte da sua estrutura de governança, a dissolução do Cofa e do CTFA; e 2) a imposição do Ministério do Meio Ambiente em usar parte do dinheiro para indenizar proprietários rurais que possuem terrenos dentro de unidades de conservação, o que contraria diretrizes de financiamento já estabelecidas. O resultado é o fechamento do ano de $2019 \mathrm{com}$ R \$ 1,54 bilhão paralisado no Fundo Amazônia, e pela primeira vez, sem nenhum novo projeto anual aprovado.

Em maio de 2020, o vice-presidente Hamilton Mourão, na presidência do reativado Conselho Nacional da Amazônia, afastou o ministro Salles das negociações com os doadores internacionais, e retomou o diálogo com os embaixadores da Noruega e da Alemanha no Brasil. Mesmo com a retirada desse interlocutor e com uma nova proposta de governança para o Fundo Amazônia, não houve consenso. Além dos problemas relacionados ao desmonte da governança anterior, a imagem negativa do governo brasileiro na Europa e o agravamento da crise ambiental são obstáculos significativos que impedem a retomada do Fundo Amazônia.

A Comissão Econômica para a América Latina e o Caribe (Cepal) conduziu recentemente um estudo que avaliou a efetividade do Fundo Amazônia. O estudo analisou em que medida os objetivos do Fundo Amazônia foram alcançados a partir dos resultados atingidos no período entre 2008 e 2018. O foco da análise foi a efetividade do funcionamento do Fundo Amazônia em seu modelo 
de governança, objetivos gerais e implementação do conjunto de projetos, sem entrar no mérito dos resultados em cada programa apoiado, isoladamente (Garcia et al., 2019). Avaliações externas como essa são de grande relevância para compreender a efetividade de experimentos em larga escala no financiamento de ações climáticas, além de legitimar iniciativas e aprendizados dos países receptores de recursos de REDD+ no contexto das negociações da UNFCCC.

\section{O discurso e a prática}

Desde a campanha presidencial em outubro de 2018, o atual chefe de governo priorizava o questionamento da fiscalização ambiental, por ele julgada excessiva. Suas declarações foram concretizadas em ações a partir do início do mandato, na contramão da sustentabilidade. Passou a desorganizar governança e os arranjos de implementação construídos de forma participativa, com diversos atores, ao longo das últimas décadas.

O ministro do Meio Ambiente, Ricardo Salles, é agente principal dessa opção governamental. Empenha-se em "passar a boiada" para desburocratizar as políticas ambientais no Brasil, por meio da mudança do regramento e flexibilização de normas, conforme declarou em reunião ministerial em abril de 2020. Algumas das ações da governança ambiental nos primeiros meses do governo incluem: a extinção da Secretaria de Mudanças Climáticas e Florestas do MMA; a extinção da Subsecretaria Geral de Meio Ambiente, Energia e Ciência e Tecnologia do Ministério das Relações Exteriores; a militarização da diretoria e de chefias regionais do Instituto Chico Mendes de Conservação da Biodiversidade (ICMBio); a exoneração, substituição lenta e incompleta dos 27 superintendentes estaduais do Instituto Brasileiro do Meio Ambiente e dos Recursos Naturais Renováveis (Ibama); a transferência do Serviço Florestal Brasileiro (SFB) do MMA para o Ministério da Agricultura, entidade responsável por gerir a concessão de florestas públicas e a implementação do Cadastro Ambiental Rural (CAR), registro eletrônico obrigatório para os proprietários de imóveis rurais e mecanismo fundamental para implementar o Código Florestal

Levantamento feito pelo Instituto Talanoa e pela Folha de S.Paulo, com base em dados extraídos do Diário Oficial, evidencia que o governo federal acelerou a publicação de atos sobre meio ambiente durante os meses de maior crescimento da pandemia da Covid-19 no país. Entre março e maio de 2020, o Poder Executivo publicou 195 atos (portarias, instruções normativas, decretos e outras normas) no Diário Oficial relacionados ao tema ambiental. Nos mesmos meses de 2019, apenas 16 atos foram publicados - um aumento de 12 vezes em 2020. A análise aponta que uma parte dessas medidas infralegais tentou mudar o entendimento da legislação, convergindo com as intenções declaradas por Salles em abril de 2020 (Amaral et al., 2020).

O Inpe, reconhecido internacionalmente por sua transparência, rigor científico e excelência na condução de pesquisas espaciais na observação da Terra por imagens de satélite, tem sido alvo de sucessivas intervenções. No início do atual 
governo, a retórica da desconfiança e descrédito dos programas da instituição, em especial aos sistemas de monitoramento das florestas, teve como objetivo levar desinformação sobre o desmatamento da Amazônia. O enfraquecimento do Inpe é evidenciado por diversos atos relacionados a anúncios do aumento da taxa do desmatamento da Amazônia Legal, iniciado com a exoneração do cientista Ricardo Galvão da presidência da instituição em agosto de 2019 após confrontar declarações do presidente sobre dados do desmatamento da Amazônia. Lubia Vinhas, coordenadora geral do Programa de Observação da Terra do Inpe e responsável por monitorar o desmatamento da Amazônia, também foi exonerada da sua função, em julho de 2020, após divulgar o aumento da taxa do desmatamento da Amazônia em 34\% no período 2018-2019.

Os dados do Inpe são questionados pelo atual governo sempre que apresentada uma forte tendência de aumento do desmatamento, o que chegou à divulgação de planos para terceirizar o monitoramento. Importante ressaltar que o Brasil é líder mundial em monitoramento de florestas tropicais. O Programa de Monitoramento do Desmatamento (Prodes), criado em 1989, calcula anualmente a taxa de desmatamento na Amazônia e disponibiliza no seu website dados para milhares de estudos científicos no mundo, o que traz transparência às ações de controle de desmatamento e preservação do bioma amazônico. Foi com base em rigor científico, transparência e confiança depositados nos sistemas de monitoramento do Inpe que a comunidade internacional reconheceu a redução de mais de $80 \%$ do desmatamento entre 2004 e 2012 , e transferiu para o Brasil quase US\$ 1,4 bilhão em pagamentos por resultados. Por esses motivos, a prestigiosa revista Science publicou, em 2007, que “o sistema de monitoramento do Brasil é a inveja do mundo" (Aguiar et al., 2020).

Em episódio recente, a Agência Espacial Brasileira, subordinada ao Ministério de Ciência, Tecnologia e Inovações, cortou para zero o orçamento de pesquisa, desenvolvimento e capital humano do Inpe para 2021. Angelo (2020) analisa a estratégia de comunicação que vem sendo aperfeiçoada pelo governo federal para atingir o Inpe e o Ibama, onde "o primeiro passo é a difamação do órgão que se quer desmontar". O autor informa que o passo seguinte é chegar às redes sociais, trocar dirigentes, cortar verbas e chamar militares para a burocracia dos órgãos de execução de suas políticas.

O presidente e seus apoiadores no Parlamento usam uma retórica inspirada em teorias conspiratórias. Afirmam que a ocupação predatória da Amazônia é desejada por outros países, e que a soberania da região e suas riquezas estão em jogo. No alto escalão do governo, os ministros das Relações Exteriores e do Meio Ambiente se apropriam do discurso nacionalista para defender a autonomia do país e rejeitar qualquer diálogo com organizações e governos internacionais sobre a questão da Amazônia. A tese é muitas vezes pautada pela ideia de que há um complô de outras nações para impedir que o Brasil seja a maior potência agrícola do mundo. Sustentam-se tais estratégias nas redes sociais que 
levam desinformação por meio do negacionismo da ciência e da incompatibilidade do desenvolvimento da região amazônica com a preservação ambiental.

A ministra Tereza Cristina (Agricultura) apresenta uma retórica diferente, alinhada à importância das práticas de sustentabilidade no agronegócio, implementação efetiva do Código Florestal, e cumprimento dos acordos internacionais em meio ambiente para mitigar riscos econômicos e assegurar a reputação do Brasil no mercado internacional. O Código Florestal (Lei n.12.651/2012) estabelece normas para proteção da vegetação nativa e as que podem ser usadas para agricultura e pecuária, com a previsão de punições para o proprietário de terras em caso de infrações. Mas o Código ainda não foi implementado de maneira efetiva, porque a maior parte dos estados não consegue completar o Cadastro Ambiental Rural (CAR).

O PPCDAm, principal instrumento da política ambiental brasileira desde 2003, referência internacional por coordenar ações interministeriais e responsável pela queda de $83 \%$ do desmatamento de 2004 a 2012, foi descontinuado pelo governo atual e extintas suas estruturas de governança. No final de 2019, após a repercussão internacional do aumento da taxa do desmatamento na Amazônia, seguido da pressão de investidores internacionais e ameaças de boicotes de mercados internacionais no consumo de produtos brasileiros, foi criada a Comissão Executiva para Controle do Desmatamento Ilegal e Recuperação da Vegetação Nativa (Decreto n.10.142/2019). Essa Comissão se sobrepõe ao Conselho Nacional da Amazônia, criado em 1995, mas restabelecido em desde fevereiro de 2020 (Decreto n.10.239/2020). Essas duas instâncias não apresentaram até o setembro de 2020 nenhum plano para combater o desmatamento em substituição ao PPCDAm.

Em maio de 2020, o Ministério do Meio Ambiente lançou (no website da vice-presidência da República) um documento intitulado Plano Nacional para Controle do Desmatamento Ilegal e Recuperação da Vegetação Nativa 20202023, como um "Anexo do Resumo Informativo n.3" (MMA, 2020). O intitulado Plano é um documento de 19 páginas com intenções, mas sem objetivos, metas e métricas mensuráveis. Não há informações sobre investimento necessário, fontes de recursos, e nem sobre os responsáveis por sua implementação. Não houve sequer consulta pública na elaboração do documento, diferentemente do PPCDAm, que contou com uma ampla participação de órgãos e entidades públicas federais, dos estados da Amazônia Legal, do setor privado e da sociedade civil.

O reativado Conselho Nacional da Amazônia Legal é coordenado pelo vice-presidente Hamilton Mourão. O colegiado é formado pelo chefe da Casa Civil da Presidência da República, pelos ministros da Justiça e Segurança Pública; da Defesa; das Relações Exteriores; da Economia; da Infraestrutura; da Agricultura, Pecuária e Abastecimento; de Minas e Energia; da Ciência, Tecnologia, Inovações e Comunicações; do Meio Ambiente; do Desenvolvimento Regional; do chefe da Secretaria Geral da Presidência da República; da chefe da Secretaria 
de Governo da Presidência da República; e do chefe do Gabinete de Segurança Institucional da Presidência da República (Decreto n.10.239/2020).

O colegiado tem como atribuições coordenar e integrar as ações governamentais na Amazônia Legal, propor políticas e iniciativas relacionadas à preservação, à proteção e ao desenvolvimento sustentável, de forma a contribuir para o fortalecimento das políticas de Estado e assegurar a ação transversal e coordenada da União, dos estados, dos municípios, da sociedade civil e do setor privado. No entanto, não há um plano de combate ao desmatamento e nem métricas a serem atingidas. Mesmo que o vice-presidente Mourão seja visto como uma voz pragmática e aberta ao diálogo no âmbito do Conselho Nacional da Amazônia, as discussões conduzidas são baseadas em intenções.

Uma das primeiras ações do Conselho foi o estabelecimento da Garantia da Lei e da Ordem (GLO) na Amazônia. Mas sua eficácia é contestada especialmente por entidades da sociedade civil, alegando que os militares não têm o conhecimento técnico necessário, como os agentes do Ibama têm, para lidar com os criminosos que queimam e derrubam a floresta. Outra iniciativa do Conselho foi o decreto de moratória do fogo em julho de 2020, proibindo por 120 dias o uso das queimadas em território nacional, mesmo as queimadas legais. Mas a efetividade da medida é questionável quando se avalia a capacidade de monitoramento do governo.

Levantamento feito por Marcelo Leite (2020), com base em documentos disponibilizados pelo Ibama, indica que a agência ambiental tem atualmente 693 fiscais treinados para o combate do desmatamento no bioma amazônico. No entanto, 140 fiscais estavam impedidos de trabalhar por terem mais de 60 anos e integrarem grupo de risco para Covid-19, 241 foram afastados por terem doenças crônicas ou conviverem em casa com idosos, grávidas e criança. Sendo assim, o contingente efetivo é de 312 fiscais para 4,2 milhões de $\mathrm{km}^{2}$ da floresta amazônica - um fiscal para mais de $13 \mathrm{mil} \mathrm{km}^{2}$.

A ineficácia da GLO, da presença do Exército na Amazônia em substituição ao Ibama, que foi subordinado aos militares, e da moratória da queimada é evidenciada por dados do Inpe que apontam a contínua tendência do aumento da taxa do desmatamento e das queimadas. O mês de agosto de 2020 teve 29.037 focos de calor na Amazônia Legal, o segundo número mais alto nos últimos dez anos, ficando $5 \%$ abaixo dos 30.900 de 2019. Entre maio e agosto, período de presença do Exército na Amazônia, o número de queimadas foi de 39.187, enquanto em 2019 foram 38.952 focos. E o número de alertas de desmatamento na Amazônia em 2020 foi 34\% maior do que em 2019. Esses dados reforçam que a presença das Forças Armadas, sem um plano integrado de combate ao desmatamento, não apresenta resultados na queda da taxa do desmatamento (Inpe, 2020; Observatório do Clima, 2020).

Outro dado alarmante significativo é que o número de multas por infração ambiental aplicadas pelo Ibama no Brasil reduziu 34\% em 2019, comparado com 2018. Dados coletados em março de 2020 indicam o registro de 9.745 
autuações ambientais no ano passado, ante 14.699 em 2018. As infrações representaram, em 2019, um total de R $\$ 2,3$ bilhões. Em 2018, foram R $\$ 4,09$ bilhões, considerada a correção inflacionária. Em valores, a queda é de 43,3\%. Os cortes orçamentários levaram à redução de fiscais e operações. Sueli Araújo, ex-presidente do Ibama, avalia que a retórica agressiva e a narrativa antifiscalização do governo federal justifica esses dados, pois os agentes do Ibama que vão a campo se sentem ameaçados e desmotivados (Brant; Watanabe, 2020). O resultado é esse aumento de $34 \%$ na taxa de desmatamento na Amazônia Legal no período 2018-2019 (Inpe, 2020).

O vice-presidente Mourão apresenta competência de relações públicas no diálogo com o setor privado e como apaziguador da crise na Amazônia. Tem realizado oportunas reuniões com investidores internacionais e empresários brasileiros. Cabe sugerir que agregue uma estratégia que traga resultados concretos e verificáveis no combate ao desmatamento.

\section{A emergência da pauta ambiental na agenda econômica}

A atual crise ambiental no Brasil tem contribuído para a tendência de aumento do desmatamento da Amazônia, afastado investidores internacionais, levado empresas internacionais a boicotar produtos brasileiros, e demonstrado a urgência por uma agenda econômica nacional atrelada à conservação ambiental.

A escalada da destruição da floresta e a fragilização da política ambiental gera uma imagem crescentemente negativa do Brasil no mercado internacional, o que preocupa líderes mundiais e empresários brasileiros pelos riscos econômicos e sistêmicos nos negócios. Organizações da sociedade civil, personalidades, gestores de fundos de investimento, políticos e governantes internacionais têm externalizado preocupação e indignação com a dimensão da crise ambiental no Brasil desde 2019, como o presidente da França, Emmanuel Macron, a chanceler alemã Ângela Merkel, e chefes de nações no âmbito do Acordo UE-Mercosul.

Desde 2019, grupos varejistas, ativistas e até países-membro da União Europeia vêm endurecendo o discurso a favor do boicote a produtos brasileiros, em resposta à política ambiental do nosso governo. Exemplos de boicotes são evidenciados pelo Centro das Indústrias de Curtumes do Brasil (CICB), com o anúncio de 18 marcas de roupas e calçados internacionais, como Timberland, Kipling, Vans e The North Face, que suspenderam as compras de couro do Brasil por conta das queimadas na Amazônia (Exame, 2019). Organizações da sociedade civil (por exemplo a ONG alemã Campact) e ativistas europeus lançam campanhas que pedem boicote a alimentos produzidos em áreas desmatadas no Brasil, e pedem que supermercados europeus, especificamente as redes varejistas Aldi Nord, Edeka e Lidl, parem de comprar alimentos brasileiros de empresas que queimam a floresta (Pinto, 2020).

A escalada da crise ambiental no Brasil pode colocar em risco a ratificação do Acordo UE-Mercosul, que foi negociado por mais de vinte anos. Estudo recente sobre as circunstâncias atuais do desmatamento da Amazônia e da política 
ambiental no Brasil, requisitado pelo Parlamento Europeu, analisa as ações que estão sendo tomadas pelo governo brasileiro no combate ao desmatamento, os programas de cooperação internacionais vigentes na região, e os desafios relacionados à inclusão de cláusulas condicionantes à preservação ambiental no Acordo UE-Mercosul. O estudo é de junho de 2020 (Müller, 2020) e foi coordenado pela Direção Geral de Política Externa do Parlamento Europeu. As análises e recomendações subsidiarão os trabalhos dos parlamentares, com o objetivo de orientar possíveis ações a serem tomadas.

O documento desenha a perspectiva de oportunidade, na qual o Acordo UE-Mercosul pode impulsionar uma nova política comercial com o Brasil, por meio de cláusulas condicionantes relacionadas ao meio ambiente e direitos humanos, incluindo objetivamente questões complexas como a perda da biodiversidade e mudanças climáticas, não previstas em outros acordos comerciais. $\mathrm{E}$ isso demandará uma mudança de mentalidade e no modus operandi. O estudo recomenda, por exemplo, o alinhamento do Acordo Geral de Tarifas e Comércio (GATT) da Organização Mundial do Comércio (OMC) a outros instrumentos como o Acordo de Paris e a Convenção sobre Diversidade Biológica (CDB), por meio de acordos comerciais vinculantes que reconheçam e valorizem os serviços ecossistêmicos (ibidem).

Sugere-se no estudo em referência que o acordo comercial entre a UE e o Mercosul incorpore modelos de parceria com o setor privado, que fomente o desenvolvimento econômico com a preservação ambiental, e que elimine o consumo de produtos oriundos do desmatamento. E isso requer, além de cláusulas condicionantes à apresentação ambiental, o rastreamento das cadeias de valor dos produtos brasileiros, para que esses sejam transparentes para os consumidores europeus, garantindo que são livres do desmatamento. Essa construção deve ser alinhada com a legislação da UE para as cadeias de abastecimento em países com florestas tropicais (ibidem). Um ponto que o vice-presidente poderia discutir com os representantes do setor produtivo.

Outro fato novamente enfatizado é o início do desinvestimento de fundos no Brasil. O fundo soberano da Noruega, maior do mundo, reduziu seu investimento no Brasil em alguns bilhões de dólares no primeiro semestre de 2020, coincidindo com as pressões crescentes de grandes fundos internacionais pela proteção da Amazônia (Norges Bank, 2020). Em um outro caso, sob a liderança da norueguesa Storebrand Asset Management, um grupo de 29 fundos de investimentos que administram cerca de US\$ 3,7 trilhões em ativos no mundo enviaram uma carta aberta às embaixadas brasileiras de oito países (Estados Unidos, Japão, Noruega, Suécia, Dinamarca, Reino Unido, França e Holanda), demonstrando profunda preocupação com a tendência do aumento do desmatamento no Brasil. Os gestores de ativos disseram que a timidez do governo brasileiro em proteger as florestas de seus agressores pode obrigá-los a reconsiderar seus investimentos devido à incerteza generalizada sobre as condições para investir e fornecer recursos financeiros ao país (Bloomberg, 2020). 
A pressão internacional é crescente e consistente. Em 15 de setembro de 2020 embaixadores de oito países europeus (Alemanha, Dinamarca, França, Itália, Holanda, Noruega, Reino Unido e Bélgica) enviaram carta ao vice-presidente Mourão afirmando que o desmatamento em alta da Amazônia dificulta fazer negócios com o Brasil. Com exceção da Bélgica, os outros sete países signatários compõem a Parceria das Declarações de Amsterdã. A iniciativa busca a eliminação do desmatamento associado às cadeias agrícolas de suprimento da Europa. Segundo os signatários, "enquanto os esforços europeus buscam cadeias de suprimento não vinculadas ao desflorestamento, a atual tendência crescente de desflorestamento no Brasil está tornando cada vez mais difícil para empresas e investidores atender a seus critérios ambientais, sociais e de governança”. Os embaixadores cobram uma ação imediata do Brasil para conter o desmatamento da Amazônia (Amsterdam Declarations Partnership, 2020).

Certamente o presidente do Conselho Nacional da Amazônia sabe que, no setor privado, a precificação dos riscos ambientais, em especial aqueles relacionados com a crise climática, vem fortalecendo os compromissos empresariais para o desenvolvimento sustentável. Os fatores de risco ambiental, social e de governança (ESG na sigla em inglês) estão recebendo atenção mundial por se associarem a negócios sólidos e resilientes contra riscos relacionados às mudanças climáticas e sustentabilidade. A análise dos fatores de riscos ESG tem sido considerada por fundos de investimento internacionais, entrando na pauta prioritária dos conselhos de administração e nas empresas com visão de futuro.

Esse movimento tem crescido no Brasil desde janeiro de 2020 quando Larry Fink, presidente da BlackRock, que faz a gestão de mais de US\$ 7 trilhões de ativos no mundo, divulgou na sua carta anual que passará a considerar o risco climático e práticas de sustentabilidade na construção de portfólio e gestão de riscos da gestora de fundos. Critérios relacionados à sustentabilidade fazem parte do novo padrão de investimento da empresa. Além disso, a BlackRock já restringiu o investimento em 53 empresas que não demonstraram progresso no combate ao aquecimento global, e anunciou a saída progressiva de investimentos em dívidas e ações de produtores de carvão térmico em suas carteiras ativas, cerca de US\$ 1,8 trilhão em ativos (Blackrock, 2020).

Como resultado da crescente pressão externa pela conservação ambiental no Brasil, em especial pelo combate ao desmatamento da Amazônia, diversas manifestações locais têm contribuído significativamente para a inserção da pauta ambiental na agenda econômica. Uma das iniciativas relevantes é o anúncio da carta intitulada "Convergência pelo Brasil", lançada em julho de 2020. Trata-se de um manifesto endereçado aos brasileiros, assinado por treze ministros da Fazenda e presidentes do Banco Central no Brasil, com o objetivo de mobilizar e convergir esforços para a recuperação da economia pós-Covid-19, por meio de oportunidades que promovam a economia de baixo carbono e sustentável, em um momento em que o mundo atravessa importantes e rápidas transformações nos mercados de capital e de trabalho (Tombini et al., 2020). 
Segundo os signatários da carta, a convergência necessária deve ser pautada por uma economia mais resiliente aos impactos da mudança do clima, e que sejam integrados à gestão da política econômica. Zerar o desmatamento na Amazônia e no Cerrado é uma das proposições do manifesto. Os signatários enfatizam que o impacto reputacional do desmatamento sobre o país tem levado diversos parceiros comerciais importantes e investidores estrangeiros a expressarem descontentamento e preocupação, que levarão a menores fluxos de comércio e investimentos no país (ibidem).

A repercussão internacional da crise ambiental no Brasil deu força a importantes manifestações locais envolvendo o setor privado, cujos princípios da sustentabilidade agora estão pragmaticamente associados ao crescimento econômico, e não apenas à agenda da conservação ambiental. Além da pressão do mercado internacional, o aumento da relevância em preservar a Amazônia tem sido objeto de estudo do Observatório da Federação Brasileira dos Bancos (Febraban). O estudo aponta que $90 \%$ dos entrevistados se dizem preocupados com a preservação da Amazônia, que é considerada essencial para a identidade nacional por $94 \%$ dos entrevistados, o que justifica o dado de que $83 \%$ se preocupam e apoiam o endurecimento das punições pelo desmatamento da Amazônia (Febraban-Ipespe, 2020).

Empresas com visão de futuro e compreensão dos riscos sistêmicos e econômicos com a escalada da crise ambiental e de imagem do país no exterior começam a demonstrar preocupação inédita em relação aos rumos da política ambiental brasileira. Presidentes de empresas começam a pressionar o governo federal em diversas instâncias, incluindo a vice-presidência, o Congresso Nacional, o Supremo Tribunal Federal e a Procuradoria Geral da República. Diversas reuniões têm sido realizadas, desde o início de 2020, quando empresários brasileiros começaram a pressionar o governo a adotar políticas efetivas de proteção ambiental, em especial no combate ao desmatamento.

Uma das principais mobilizações empresariais do país é formada pelas organizações Conselho Empresarial Brasileiro para o Desenvolvimento Sustentável (CEBDS), Associação Brasileira do Agronegócio (ABAG), Indústria Brasileira da Árvore (IBÁ), e Associação Brasileira das Indústrias de Óleo Vegetal (Abiove). No dia 6 de julho de 2020 o movimento, formado por essas instituições e por mais de 40 empresas signatárias, encaminhou à vice-presidência da República e ao Conselho Nacional da Amazônia Legal uma carta intitulada "Comunicado do Setor Empresarial Brasileiro". Trata-se de um comunicado em defesa da agenda do desenvolvimento sustentável e combate ao desmatamento na Amazônia. $\mathrm{O}$ documento conta com as assinaturas dos CEO das companhias e grupos empresariais aderentes ao movimento, e que representam os setores industrial, agrícola e de serviços. O documento também foi entregue ao Supremo Tribunal Federal, Senado Federal, Câmara dos Deputados e na Procuradoria Geral da República. A carta demonstra preocupação e aponta ações imediatas que devem 
ser adotadas para reduzir as reações negativas de investidores e consumidores estrangeiros ao país (CEBDS, 2020).

Registre-se que representantes de mais de 40 empresas globais nos setores de finanças, agronegócio, hotelaria, turismo e varejo assinaram uma carta aos parlamentares, pedindo a rejeição do "PL 2633" ou "PL da Grilagem” e ameaçando boicotar o Brasil. Entre as signatárias estão o Fundo de Pensão sueco AP7, a seguradora norueguesa Storebrand, as redes de alimentos Burger King, Nandos, Waitrose, além das redes de supermercados Sainsbury's, Tesco, Morrisons e Marks \& Spencer (Nunes, 2020).

O setor financeiro brasileiro, além da pressão sob o governo, apresenta uma proposta de apoio ao desenvolvimento de uma agenda sustentável no país. Os presidentes do Itaú, do Bradesco e do Santander anunciaram um compromisso de apoiar o desenvolvimento sustentável da Região Amazônica. O plano, apresentado ao governo federal em 22 de julho de 2020, compreende dez medidas com três eixos estratégicos: conservação ambiental e desenvolvimento da bioeconomia; investimento em infraestrutura sustentável; e contribuição para a garantia dos direitos básicos da população (Guimarães, 2020). Para a operacionalização do plano, os três bancos privados anunciaram uma estrutura de governança inicial liderada por um Conselho Consultivo. Esse colegiado mobiliza sete notáveis (cientistas, ambientalistas e pecuaristas), para ajudar a desenhar políticas para financiar o desenvolvimento sustentável da Amazônia.

A iniciativa do Itaú Unibanco, do Bradesco e do Santander suscita uma rastreabilidade capaz de impedir o crédito bancário aos agentes da cadeia produtiva que contribuam para o desmatamento. Isso certamente afetará a parte nociva da grande pecuária. Talvez, como na moratória da soja, fosse possível punir produtos beneficiários diretos ou indiretos do desmatamento. Cabe dizer, a propósito, que as ações do governo, provocadoras da suspensão do Fundo Amazônia, resultaram no "defund" para os projetos oficiais ou privados em favor da sustentabilidade na região.

No contexto de autorregulação do setor financeiro no Brasil e no mundo, duas iniciativas são destacadas. A primeira refere-se a um relatório de autoria do Bank for International Settlements (BIS) que aborda riscos financeiros associados às mudanças climáticas, do qual o Banco Central do Brasil é membro. O BIS, considerado "o banco dos bancos centrais", é uma organização internacional responsável pela supervisão bancária que visa promover a cooperação entre os bancos centrais e outras agências na busca de estabilidade monetária e financeira, além de promover a cooperação monetária e financeira internacional. Sediado em Basileia, na Suíça, reúne 55 bancos centrais de todo o mundo. O relatório aponta que a maioria dos membros do BIS considera os riscos financeiros relacionados ao clima dentro de suas estruturas regulatórias, possui iniciativas de medição dos riscos financeiros associados ao clima e divulga informações relacionadas. O Comitê de Supervisão Bancária da Basileia estabeleceu recentemente 
uma Força-Tarefa sobre Riscos Financeiros Relacionados ao Clima (TFCR). O TFCR é responsável por contribuir para o mandato do Comitê que visa melhorar a estabilidade financeira global com foco em mitigar os riscos financeiros relacionados ao clima (BIS, 2020).

A segunda iniciativa, que provavelmente decorre da primeira, refere-se ao lançamento da Agenda ESG (Environmental, Social, Governance) do Banco Central do Brasil, no dia 8 de setembro de 2020. A agenda contempla ações mais imediatas, como a incorporação de cenários de riscos climáticos em testes de estresse do $\mathrm{BC}$, e medidas de médio e longo prazos como exigências regulatórias para as instituições financeiras a partir de 2022, conforme recomendações da TFCR. A criação de uma linha financeira de liquidez sustentável para instituições financeiras e a inclusão de critérios de sustentabilidade para seleção de contrapartes na gestão das reservas e seleção de investimento também foi anunciado. Esse contexto evidencia que os três grandes bancos brasileiros almejam se alinhar com normas estabelecidas, ou em fase estabelecimento, no âmbito internacional e nacional.

Os bancos se juntam a investidores internacionais e empresas brasileiras que têm demonstrado preocupação com o nexo entre a questão ambiental e a agenda econômica brasileira. A mobilização empresarial e da sociedade civil organizada é crescente e consistente. Em setembro de 2020, a Coalizão Brasil Clima, Florestas e Agricultura, o CEBDS, o Instituto Ethos, a Rede Brasil do Pacto Global da ONU e o Sistema B lançaram o documento "10 Princípios Empresariais para uma Amazônia Sustentável", baseado na premissa de que preservar e produzir não são verbos antagônicos nos biomas brasileiros, em especial a região amazônica. Os signatários reforçam o papel propulsor das empresas no desenvolvimento territorial sustentável e no fortalecimento de um ecossistema com maior qualidade socioeconômica para a Amazônia. $\mathrm{O}$ documento pretende ser um norteador para empresas que desejam operar de forma mais sustentável na região amazônica e um roteiro para embasar o planejamento estratégico e o exercício de priorização de projetos, com impactos positivos nas cadeias produtivas (Badziack et al., 2020).

Por outro lado, é importante mencionar que há alguns grupos empresariais que apoiam a política ambiental praticada, e que declaram apoio unânime e irrestrito ao ministro Salles, incluindo associações que representam a indústria da construção civil como o Sindicato da Indústria da Construção Civil (Sinduscon), em diversos estados brasileiros. No dia 26 de maio de 2020, mais de oitenta organizações patronais publicaram um anúncio de página inteira em jornais de grande circulação declarando "total apoio" às políticas do Ministério do Meio Ambiente. Setores importantes do agronegócio, representantes empreiteiros e do mercado imobiliário estão entre os signatários do manifesto, incluindo a Confederação Nacional da Agricultura (CNA), a Confederação Nacional da Indústria (CNI), a Associação dos Produtores de Soja (Aprosoja), a Sociedade Rural Brasileira (SRB), a União da Indústria de Cana de Açúcar (Única), entre outros (Castilho, 2020). 


\section{Agenda propositiva para a retomada do Fundo Amazônia}

Este estudo evidencia, invocando fatos e atos, que a condução da política ambiental vigente contraria empresas e afeta negativamente a economia do país. O Brasil posiciona-se de forma a inviabilizar a ratificação de importantes acordos comerciais internacionais, como é o caso do UE-Mercosul. Se esse acordo foi antes endossado pelo atual governo como política de Estado construída por vários governos ao longo de vinte anos, por que não adotar a mesma atitude agora em relação à Amazônia?

A governança ambiental do Brasil e seus arranjos de implementação precisam ser restabelecidos. Não faltam respaldos legais e planos de combate ao desmatamento e incentivo ao desenvolvimento sustentável, especialmente no bioma amazônico. As ações demandam objetivos claros, métricas mensuráveis, previsão orçamentária e definição de atores públicos e privados responsáveis por sua implementação. Precisamos mostrar resultados para a retomada da credibilidade do Brasil perante investidores internacionais e doadores do Fundo Amazônia. A coordenação harmoniosa nas esferas ministerial e subnacional é determinante para a execução eficiente da política ambiental do Estado brasileiro. Proteger os biomas contra ilegalidades é dever constitucional. E o Fundo Amazônia, com significativa capacidade de investimento para financiar projetos que lidem com esses problemas, está suspenso desde 2019, com R \$ 1,54 bilhão paralisado.

A intensidade da crise ambiental, que agora faz parte da agenda econômica no país, exige a solução urgente do impasse que envolve este mecanismo. Sem a reconstituição do Cofa, do CTFA, e dos arranjos institucionais de governança participativa que incluam representantes da sociedade civil, o Fundo não será retomado por parte dos doadores internacionais.

A fragilização do Ibama, a redução do número de multas, embargos e execução orçamentária contribuem diretamente para o aumento da taxa do desmatamento. Diversos estudos correlacionam a redução das emissões de GEE na Amazônia com o número de sanções, multas e políticas efetivas de comando e controle (Assunção et al., 2015, p.697-722; Sousa, 2016). Assim, a retomada do Fundo Amazônia deve associar-se ao restabelecimento da governança ambiental e de um plano efetivo de prevenção contra o desmatamento, como foi o PPCDAm, atrelado ao desenvolvimento sustentável por meio do fomento a uma economia de baixo carbono. Um Conselho Nacional da Amazônia apenas com intenções não responderá à complexidade de seus objetivos que definitivamente integram a agenda econômica do país.

Cabe realçar que, apesar da paralisação do Fundo Amazônia, o BNDES apresentou relatório de atividades de 2019 de maneira transparente, apontando seus diversos aprendizados ao cumprir o papel de gestor financeiro e prestando contas aos doadores. A avaliação técnica e construtiva da Cepal sobre a efetividade desse meio de pagamento ambiental traz um conjunto importante de recomendações para que o programa recomece em novo patamar, com base nas lições acumuladas, 
tendo em vista o que funcionou e o que deve ser aprimorado. O principal pilar para a retomada do Fundo é o restabelecimento da sua governança (Cofa e CTFA).

Aqui se propõe que a retomada seja condicionada ao cumprimento dos compromissos assumidos pelo Brasil no Acordo de Paris e demais protocolos de cooperação internacional, especialmente no âmbito do UE-Mercosul. União Europeia e Argentina, Brasil, Paraguai e Uruguai concluíram as negociações do acordo comercial UE-Mercosul em 28 de junho de 2019, após vinte anos de negociações. Esse Acordo, como sabem as autoridades, prevê a redução imediata ou gradual de tarifas de importação entre os países europeus e sul-americanos. A meta da reorganização tarifária é tornar mais baratos os produtos agropecuários e industriais abrigados sob o guarda-chuva do acordo. É visível, portanto, o conjunto de benefícios ao Brasil e demais países signatários.

O Acordo tem um capítulo específico sobre a economia verde, focando questões como a gestão e a conservação das florestas, o respeito aos direitos laborais e a promoção de negócios sustentáveis. Além disso, atribui às organizações da sociedade civil um papel ativo na supervisão do cumprimento do acordo e em eventuais pendências ambientais. Há uma referência explícita ao Acordo de Paris, no qual as partes se comprometem a trabalhar contra as mudanças climáticas, fomentar a transição para uma economia de baixo carbono e combater a degradação florestal. Compromissos vinculados à proteção ambiental em outros acordos multilaterais são mencionados, como a Convenção sobre o Comércio Internacional das Espécies de Fauna e Flora Selvagens Ameaçadas de Extinção (Cites) e a Convenção sobre Diversidade Biológica (CDB). Prevê-se um conjunto de regras claras e sólidas referente aos compromissos no desenvolvimento sustentável, incluindo avaliação externa conduzida por especialistas das questões referidas no Acordo (Comissão Europeia, 2019).

É importante reiterar que gestores de fundos de investimentos internacionais, acumulando perto de US\$ 4 trilhões (mais de R $\$ 20$ bilhões), dirigiram-se ao governo federal solicitando a contenção do desmatamento e das queimadas na Amazônia. Igual pleito foi encaminhado por grandes coalizões empresariais brasileiras e os três bancos privados que lideram o nosso sistema financeiro. Não são mais apenas as $\mathrm{ONG}$, vistas pelo atual governo com desconfiança incabível, que se alinham a esse apelo em favor da sustentabilidade naquele bioma. $\mathrm{O}$ vice-presidente Mourão, se quiser deixar um legado em sua passagem pelo poder, deve zerar as incompatibilidades com a Noruega nessa matéria.

O restabelecimento do Fundo Amazônia, com a mesma autonomia de governança por parte do BNDES, mais do que o recomeço das doações, implicaria um gesto de grande e positiva repercussão, no Brasil e no exterior. Dentro do governo, cabe ao presidente do Conselho Nacional da Amazônia atuar como agente moderador, convencendo o chefe do governo e demais integrantes do colegiado que é preciso reconhecer equívocos anteriores e empreender um acordo nas negociações. 
Se todas as razões alinhadas neste artigo não forem suficientes para essa revisão, basta-lhe a leitura dos relatórios de projetos financiados pelo Fundo Amazônia. Manter a floresta em pé, que por muito tempo foi um apelo da academia e das organizações não governamentais, hoje se originam de lideranças empresariais que respeitam a soberania do Brasil. Os novos demandantes não querem um palmo de terra amazônica. Eles querem apenas que o grande bioma continue regulando a chuva no planeta; assegurando uma vida digna aos povos indígenas; desenvolvendo novos remédios a partir de sua biodiversidade específica; possibilitando chuvas abundantes em áreas produtoras do agronegócio na América do Sul; e contribuindo efetivamente para manter bons padrões climáticos no planeta.

O restabelecimento do Fundo Amazônia deve ser igualmente condicionado ao cumprimento dos princípios norteadores definidos pelo próprio Brasil nas instâncias que influenciam diretamente as políticas de combate ao desmatamento do país, incluindo o Conselho Nacional da Amazônia, o Plano Nacional para Controle do Desmatamento Ilegal e Recuperação da Vegetação Nativa (20202023) e a $4^{\text {a }}$ fase do PPCDAm (2016-2020). Esse último, embora substituído no atual governo por um plano de intenções, direcionava os critérios de investimento e seleção de projetos do Fundo Amazônia (Decreto n.6.527/2008) até 2018.

\section{Considerações finais}

Em 2020 acentuou-se o enfraquecimento do multilateralismo nas relações internacionais. A pandemia da Covid-19 mostrou a clara interdependência dos riscos globais e da necessidade de cooperação entre países para solucionar problemas complexos e cercados de incertezas. A crise sanitária mundial, a par de seus efeitos danosos, também esvaziou o ceticismo de direita, assim fortalecendo a ciência e um de seus afluentes que é a agenda de desenvolvimento verde. Chefes de Estado da União Europeia aprovaram, em julho do corrente ano, um plano de recuperação econômica pós-pandemia no valor de 750 bilhões de euros, considerando que $30 \%$ dos recursos devem ser destinados ao fortalecimento da defesa do meio ambiente e avanço da tecnologia digital. Isso mostra que a retomada verde e inclusiva vai mudar o business as usual, e deve aumentar o incentivo às atividades voltadas para uma economia de baixo carbono.

O Brasil se encontra na direção oposta de uma retomada verde no póspandemia, e provavelmente será o único grande emissor mundial que terminará o ano de 2020 com aumento das emissões por conta do desmatamento e da degradação florestal. Marcha perigosamente em sentido contrário ao cumprimento de suas metas assumidas no Acordo de Paris e aos princípios norteadores que regem o Acordo UE-Mercosul. O governo federal, em desacordo com os doadores internacionais, perde uma oportunidade para financiar, sem desembolso do erário, grande parte da política pública de combate ao desmatamento na Amazônia. Ainda há tempo, embora curto, para uma correção de rumo. 
O cumprimento dos princípios relacionados à sustentabilidade e ao meio ambiente em negociações comerciais internacionais, cooperação bilateral e multilateral tornou-se cada vez mais condição vinculante para a retomada do Fundo Amazônia. Os deveres assumidos no Acordo Mundial do Clima harmonizam-se com os objetivos institucionais do Conselho Nacional da Amazônia e do Plano Nacional para Controle do Desmatamento Ilegal e Recuperação da Vegetação Nativa (2020-2023). O setor empresarial cobra resultados que gerem impactos nessa direção. Tudo favorece uma revisão das práticas do Ministério do Meio Ambiente. E os exemplos precedentes na Amazônia devem ser vistos como políticas de Estado, não de governos transitórios. O Brasil já mostrou ao mundo sua capacidade de combater o desmatamento com inteligência, articulação entre ministérios e atores diversos, sem abrir mão do comando e do controle.

Dar continuidade às práticas anteriores na Amazônia não significa uma aprovação política à ideologia dos adversários do atual Executivo. A presente gestão vem completando e inaugurando obras iniciadas em governos passados e por isso não merece críticas. Urge uma autocrítica, enquanto é tempo. É muito importante fortalecer o Ibama, reconstituir o Fundo Amazônia e seu modelo de governança. Aí estão duas metas de curto prazo e praticamente sem custos adicionais, usando-se mecanismos de Estado já disponíveis.

O ambientalismo no Brasil, representado por uma fração mais moderada, não hesitaria em aplaudir o Conselho Nacional da Amazônia, caso chegasse a um acordo nas negociações com a Noruega. Para isso, no entanto, não é suficiente reduzir significativamente os índices de desmatamento e queimadas em consequência da ação (temporária) dos militares na Amazônia. Os doadores querem algo mais simples, cuja solução está dentro do governo: a governança do Fundo Amazônia pelos técnicos do BNDES que acumularam, nos últimos anos, considerável expertise na matéria. Outro item a definir é uma política ambiental de longo prazo, que reduza o desmate ilegal a zero até 2030 como está explícito na CND firmada pelo Estado brasileiro no Acordo de Paris.

Esse é também o entendimento da questão por parte da sociedade civil, que ao contrário do que julgam apoiadores mais radicais do governo federal, não é o oposto de sociedade militar. Para usarmos a definição liberal de Norberto Bobbio, um dos mais notáveis cientistas políticos do século XX, sociedade civil "é a esfera de relações entre indivíduos, entre grupos, entre classes sociais, que se desenvolvem à margem das instituições estatais”. (Bobbio et al., 1998).

Como se vê, um segmento plural e heterogêneo, que abrange empresas, as ONG, a imprensa, cientistas, professores, estudantes, trabalhadores, profissionais liberais - todos movidos por convicções diversas, por vezes até em conflitos que requerem a mediação do Estado, visando uni-los em torno de boas escolhas. 


\section{Referências}

AGUIAR et al. Novo sistema do Inpe consolida liderança do Brasil. O Estado de $S$. Paulo, São Paulo, Economia e Negócios, 23 de jul. 2020. Disponível em: < https:// economia.estadao.com.br/noticias/geral,novo-sistema-do-inpe-consolida-lideranca-do-brasil,70003373122 >. Acesso em: 27 ago. 2020.

AMARAL, A. C. et al. Governo acelerou canetadas sobre meio ambiente durante a pandemia. Folha de S.Paulo, São Paulo, 29 jul. 2020, Ambiente, p.B1. Disponível em: <https://wwwl.folha.uol.com.br/ambiente/2020/07/governo-acelerou-canetadas-sobre-meio-ambiente-durante-a-pandemia.shtml>. Acesso em: 2 set. 2020.

AMSTERDAM DECLARATIONS PARTNERSHIP. Open Letter to Vice President Mourão from the Amsterdam Declarations Partnership. 15 set. 2020. Disponível em: <https://brasil.diplo.de/blob/2385170/4df777b4179c6e3b72d8573f76c592b4/ open-letter---amsterdam-declarations-partnership--adp--data.pdf>. Acesso em: 20 set. 2020 .

ANGELO, C. O Inpe é o novo Ibama. Direto da Ciência. 26 ago. 2020. Disponível em: <http://www.diretodaciencia.com/2020/08/26/o-inpe-e-o-novo-ibama/>. Acesso em: 30 ago. 2020.

ASSUNÇÃO, J.; GANDOUR, C.; ROCHA, R. Deforestation slowdown in the Brazilian Amazon: prices or policies. Environment and Development Economics, Cambridge University Press, v.20, n.6, p.697-722, 2015.

BADZIACK, E. et al. 10 Princípios Empresariais para uma Amazônia Sustentável. Amazônia Possível, 12 ago. 2020. Disponível em: <https://arapyau.org.br/iniciativa-amazonia-possivel-lanca-guia-dos-10-principios-empresariais-para-uma-amazonia-sustentavel/>. Acesso em: 1 set. 2020.

BANK FOR INTERNATIONAL SETTLEMENTS - BIS Climate-related financial risks - a survey on current initiatives. 30 abr. 2020. Disponível em: <https://www.bis. org/bcbs/publ/d502.htm>. Acesso em: l set. 2020.

BLACKROCK. Committed to sustainability. 2020, 1 set. Disponível em: <https:// www.blackrock.com/corporate/sustainability/committed-to-sustainability>. Acesso em: 1 set. 2020 .

BLOOMBERG. Fundos com US\$ 3,7 trilhões alertam Brasil sobre desmatamento. InfoMoney, 23 jun. 2020. Disponível em: <https://www.infomoney.com.br/onde-investir/fundos-com-us-37-trilhoes-alertam-brasil-sobre-desmatamento/>. Acesso em: 1 set. 2020 .

BNDES. Relatório de atividades 2019 - Fundo Amazônia. Rio de Janeiro, 2019. Disponível em: <http://www.fundoamazonia.gov.br/export/sites/default/pt/.galleries/ documentos/rafa/RAFA_2019_port.pdf>.

BOBBIO, N.; MATTEUCCI, N.; PASQUINO, G. Dicionário de política. 11.ed. Brasília: Editora Universidade de Brasília, 1998. v.2.

BRANT, D.; WATANABE, P. Sob Bolsonaro, multas ambientais caem 34\% para menor nível em 24 anos. Folha de S.Paulo, São Paulo, 9 mar. 2020. Ambiente. Capa e Bl. Disponível em: <https://wwwl.folha.uol.com.br/ambiente/2020/03/sob-bolsonaro-multas-ambientais-caem-34-para-menor-nivel-em-24-anos.shtml>. Acesso em: 28 ago. 2020. 
CASTILHO, A. L. Financiadores da bancada ruralista publicam anúncio em "total apoio" a Ricardo Salles. De olho nos ruralistas. 26 mai. 2020. Disponível em: <https:// deolhonosruralistas.com.br/2020/05/26/financiadores-da-bancada-ruralista-publicam-anuncio-em-total-apoio-a-ricardo-salles/>. Acesso em: 22 set. 2020.

CEBDS Setor empresarial cobra agenda sustentável do governo brasileiro. Assessoria CEBDS, 7 jul. 2020. Disponível em: <https://cebds.org/wp-content/uploads $/ 2020 / 07 /$ cebds.org-comunicado-do-setor-empresarial-brasileiro-0824-comunicado-do-setor-empresarial-pt.pdf>. Acesso em: 1 set. 2020.

COMISSÃO EUROPEIA. Elementos-chave do acordo comercial UE-Mercosul. Comissão Europeia - Perguntas e Respostas. Bruxelas. 2019. Disponível em: <https://ec.europa. $\mathrm{eu} /$ commission/presscorner/detail/pt/QANDA_19_3375>. Acesso em: 1 set. 2020.

CONSELHO NACIONAL DA AMAZÔNIA LEGAL. Proposta de Ações Imediatas. 18 de maio 2020. Disponível em: <https://www.gov.br/planalto/pt-br/conheca-a-vice-presidencia/conselho-da-amazonia/proposta-de-acoes-imediatas $>$. Acesso em: 28 ago. 2020.

EU-Mercosul. Novo acordo comercial UE- Mercosul O acordo de princípio. Bruxelas. 2019. Disponível em: <http://trade.ec.europa.eu/doclib/docs/2019/july/tradoc_158250.pdf>. Acesso em: 1 set. 2020.

EXAME. Timberland, Kipling e Vans deixam de comprar couro do Brasil, 28 de ago. 2019. Disponível em: <https://exame.com/negocios/timberland-kipling-vans-e-outras-marcas-suspendem-couro-do-brasil/\#: : text=S\%C3\%A3o\%20Paulo\%20 $\% \mathrm{E} 2 \% 80 \% 94 \% 20$ Pelo $\% 20$ menos $\% 2018$,causa $\% 20$ das $\% 2$ queimadas $\% 20$ na $\% 20$ Amaz\%C3\%B4nia>. Acesso em: 1 set. 2020.

FEBRABAN-IPESPE. A importância da Amazônia para o Brasil, os brasileiros e o mundo. Observatório Febraban. São Paulo, 2020. Disponível em: <https://portal.febraban.org.br/noticia/3509/pt-br/>.

GARCIA, J. J. G. et al. Relatório de Avaliação de Meio Termo da Efetividade do Fundo Amazônia 2008-2018. Rio de Janeiro: Fundo Amazônia/Cepal, 2019. Disponível em: <http://www.fundoamazonia.gov.br/export/sites/default/pt/.galleries/documentos/monitoramento-avaliacao/avaliacoes-externas/FA-Relatorio-Avaliacao-Meio-Termo-Fundo-Amazonia.pdf>. Acesso em: 1 jun. 2020.

GUIMARÃES, F. Bradesco, Itaú e Santander lançam plano para desenvolvimento sustentável da Amazônia. O Estado de S. Paulo, São Paulo, 22 de jul. 2020. Disponível em: <https://economia.estadao.com.br/noticias/geral,bradesco-itau-e-santander-lancam-plano-para-desenvolvimento-sustentavel-da-amazonia,70003372721 >. Acesso em: 1 set. 2020.

INPE. INPE estima $7.900 \mathrm{~km}^{2}$ de desmatamento por corte raso na Amazônia em 2018. 7 dez. 2018. Disponível em: <http://www.inpe.br/noticias/noticia.php?Cod_Noticia $=4957>$. Acesso em: 1 jul. 2020.

- Programa Queimadas. Monitoramento dos Focos Ativos por Região. Disponível em: <http://queimadas.dgi.inpe.br/queimadas/portal-static/estatisticas_ estados /?utm_source=newsletter\&utm_medium =email\&utm_campaign=queimadas_ em_agosto_confirmam_que_exercito_fracassou_na_amazonia\&utm_term=2020-0901>. Acesso em: 1 set. 2020. 
INPE. Prodes Amazônia. Monitoramento do Desmatamento da Floresta Amazônica Brasileira por Satélite. Disponível em: <http://www.obt.inpe.br/OBT/assuntos/programas/amazonia/prodes>. Acesso em: 26 ago. 2020.

LEITE, M. Agulhas no palheiro em chamas. Folba de S.Paulo, São Paulo, 29 ago. 2020. Ambiente, p. B6. Disponível em: <https://wwwl.folha.uol.com.br/colunas/marceloleite/2020/08/agulhas-no-palheiro-em-chamas.shtml>. Acesso em: 30 ago. 2020.

MARCOVITCH, J.; PINSKY, V. C. Amazon Fund: financing deforestation avoidance. Revista de Administração, v.49, n.2, p.280-90, abr./maio/jun. 2014. Disponível em: <https://doi.org/10.5700/rausp1146>. Acesso em: 1 jul. 2020.

MMA. Plano de Ação para Prevenção e Combate do Desmatamento na Amazônia Legal - Plano Operativo 2016-2020. Brasília, DF, 2016. Disponível em: <https://www.mma. gov.br/images/arquivo/80120/Anexo\%20II\%20-\%20PLANO\%20OPERATIVO\%20 DO\%20PPCDAm\%20-\%20GPTI\%20_\%20p\%20site.pdf>. Acesso em: l set. 2020.

Plano Nacional para Controle do Desmatamento Ilegal e Recuperação da Vegetação Nativa 2020-2023. Brasília, DF, 2020. Disponível em: <https://www.gov. br/planalto/pt-br/conheca-a-vice-presidencia/nota-a-imprensa/anexo-ao-resumo-informativo-no-3_de-29-5-2020.pdf/view>. Acesso em: 1 set. 2020.

Plano para Controle do Desmatamento Ilegal e Recuperação da Vegetação Nativa. Disponível em:< https://www.mma.gov.br/informma/ item $/ 616$-preven \% C 3\%A7\%C3\%A 3o-e-controle-do-desmatamento-na- amaz\%C3\%B4nia.html\#: : :text=O\%20Plano\%20de $\% 20 \mathrm{~A} \% \mathrm{C3} \% \mathrm{~A} 7 \% \mathrm{C} 3 \% \mathrm{~A} 3$ o\%2 0 para,desenvolvimento\%20sustent $\%$ C3\%Alvel\%20na\%20Amaz\%C3\%B4nia\%20Legal>. Acesso em: 1 jul. 2020.

MOUTINHO, P.; GUERRA, R.; AZEVEDO-RAMOS, C. Achieving zero deforestation in the Brazilian Amazon: What is missing? Elementa: Science of the Anthropocene, v.4, 000125, 2016. https://doi.org/10.12952/journal.elementa.000125

MÜLLER, C. Brazil and the Amazon Rainforest Deforestation, Biodiversity and Cooperation with the EU and International Forums Policy. Luxembourg: European Parliamentary Service (EPRS), mai. 2020. Disponível em: <https://www.europarl.europa.eu/RegData/etudes/IDAN/2020/648792/IPOL_IDA(2020)648792_EN.pdf>. Acesso em: 1 jul. 2020.

NORGES BANK Exclusion decisions and decisions to revoke exclusion. 13 maio 2020. Disponível em: <https://www.nbim.no/en/the-fund/news-list/2020/exclusion-decisions-and-decisions-to-revoke-exclusion/>. Acesso em: 28 ago 2020.

NUNES, M. Mais de 40 empresas globais assinam carta para pedir que parlamentares rejeitem o 'PL 2633' ou 'PL da Grilagem' e ameaçam boicotar o Brasil. Conexão Planeta. Mai. 2020. Disponível em: <https://conexaoplaneta.com.br/blog/40-empresas-globais-assinam-carta-para-pedir-que-parlamentares-rejeitem-o-pl-2633-ou-pl-da-grilagem-e-ameacam-boicotar-o-brasil/\#fechar>. Acesso em: 1 set. 2020.

OBSERVATÓRIO DO CLIMA. Queimadas em agosto confirmam que Exército fracassou na Amazônia. 1 set. 2020. Disponível em: <http://www.observatoriodoclima.eco. br/queimadas-em-agosto-confirmam-que-exercito-fracassou-na-amazonia/>. Acesso em: 1 set. 2020.

PINSKY, V. C.; KRUGLIANSKAS, I.; VICTOR, D. G. Experimentalist governance 
in climate finance: the case of REDD+ in Brazil. Climate Policy, v.19, n.6, p.725-38, 2019. https://doi.org/10.1080/14693062.2019.1571474

PINTO, A. E. S. Cresce na Europa pressão contra produtos brasileiros, em reação a queimadas na Amazônia. Folha de S.Paulo. São Paulo. 11 jul. 2020. Mercado. Disponível em: <https://wwwl.folha.uol.com.br/mercado/2020/07/cresce-na-europa-pressao-contra-produtos-brasileiros-em-reacao-a-queimadas-na-amazonia.shtml>. Acesso em: 1 set. 2020.

SOUSA, P. Q. Decreasing deforestation in the Southern Brazilian Amazon-The role of administrative sanctions in Mato Grosso State. Forests, v.7. n.3, p.66, 12 mar. 2016.

TOMBINI, A. A. et al. Uma convergência necessária: por uma economia de baixo carbono. Instituto Clima e Sociedade e Instituto O Mundo Que Queremos, 15 jul. 2020. Disponível em: <https://convergenciapelobrasil.org.br/leia-a-carta-na-integra/>. Acesso em: 1 jul. 2020.

UNFCCC. Key decisions relevant for reducing emissions from deforestation and forest degradation in developing countries (REDD+). UNFCCC Secretariat, jun. 2014. Disponível em: <http://unfccc.int/6917.php>. Acesso em: 1 jul. 2020.

WOLOSIN, M.; BREIFTFELLER, J.; SCHAAP, B. The Geography of REDD+ Finance: Deforestation, emissions, and the targeting offorest con- servation finance. Washington, DC: Forest Trends, ago. 2016. Disponível em: <http://www.forest-trends. org/documents/files/doc_5334.pdf>. Acesso em: 1 set. 2020.

RESUMO - O objetivo deste artigo é apresentar uma agenda propositiva para a retomada do Fundo Amazônia. Para isso, as práticas de (des)governança em nível federal são analisadas à luz dos compromissos assumidos pelo Brasil em acordos internacionais de cooperação. Essa análise evidencia que o cumprimento dos princípios relacionados à sustentabilidade e ao meio ambiente em negociações comerciais internacionais, cooperação bilateral e multilateral são condições vinculantes para a retomada do Fundo Amazônia. O setor empresarial, com destaque para o setor financeiro, demanda resultados relativos ao crescente desflorestamento predatório da Amazônia. Essas condições e expectativas exigem uma drástica revisão dos atos do Ministério do Meio Ambiente. O Estado brasileiro já demostrou ao mundo sua capacidade de combater o desmatamento ilegal com inteligência, articulação entre ministérios e atores diversos, reservando para si a plena responsabilidade de comando e do controle nas suas políticas ambientais.

PALAVRAS-CHAVE: Fundo Amazônia, REDD+, Financiamento do clima, Acordo de Paris, Cooperação internacional.

ABSTRACT - The aim of this article is to present a propositional agenda to restart the Amazon Fund. On this matter, the practices of (dis)governance at the federal level are analyzed with regard to the commitments taken on by Brazil in international cooperation agreements. The analysis shows that complying with principles related to sustainability and the environment in international commercial negotiations, and bilateral and multilateral cooperation are a fundamental condition to restart the Amazon Fund. The business sector, and specifically the financial sector, demands results regarding the increasing predatory deforestation of the Amazon region. These conditions and expectations 
require a drastic revision of the activities of the Ministry of Environment. The Brazilian State has already shown the world its ability to combat illegal deforestation with intelligence, cooperation between ministries and other stakeholders, ensuring clear command and control responsibility for its environmental policy.

KErWORDS: Amazon Fund, REDD+, Climate financing, Paris Accord, International cooperation.

Jacques Marcovitch é professor emérito da Faculdade de Economia, Administração e Contabilidade da Universidade de São Paulo, da qual foi reitor de 1997 a 2001. É também professor do Instituto de Relações Internacionais da USP. Integra o Conselho Deliberativo da Biblioteca Brasiliana Guita e José Mindlin em São Paulo e do Graduate Institute of International and Development Studies (IHEID), em Genebra.

@ - jmarcovi@usp.br / https://orcid.org/0000-0002-6148-7735.

Vanessa C. Pinsky é pesquisadora associada ao Programa de Pós-graduação em Administração da da Faculdade de Economia, Administração e Contabilidade da Universidade de São Paulo. Foi pesquisadora visitante na School of Global Policy \& Strategy da University of California San Diego. Professora no programa de mestrado profissional e nos cursos de especialização da Fundação Instituto de Administração (FIA). Coordenadora adjunta do Progesa-FIA. @ - vanessa.pinsky@usp.br / https://orcid.org/0000-0002-7679-2353.

Recebido em 29.9.2020 e aceito em 6.10.2020.

I, II Faculdade de Economia, Administração e Contabilidade, Universidade de São Paulo, São Paulo, Brasil. 